\title{
One-year prospective study of occupational health in the inten- sivists of a COVID-19 hub hospital
}

\author{
Nicola Magnavita ${ }^{1,2, *}$, Paolo Maurizio Soave ${ }^{1,3}$ and Massimo Antonelli ${ }^{3}$ \\ 1 Postgraduate School of Occupational Medicine, Università Cattolica del Sacro Cuore, 00168 Rome, Italy; \\ paolomaurizio.soave@policlinicogemelli.it \\ 2 Department of Woman/Child \& Public Health, Fondazione Policlinico Universitario Agostino Gemelli \\ IRCCS, 00168 Rome, Italy \\ 3 Department of Emergency, Anesthesiology and Resuscitation Sciences, Fondazione Policlinico Universitario \\ Agostino Gemelli IRCCS, 00168 Rome, Italy; massimo.antonelli@unicatt.it, \\ * Correspondence: nicolamagnavita@gmail.com or nicola.magnavita@unicatt.it; or nicola.magnavita@poli- \\ clinicogemelli.it \\ Tel.: +39-3473300367
}

\begin{abstract}
:
The COVID-19 pandemic has severely tested the physical and mental health of health care workers (HCWs). The various stages of the epidemic have posed different problems; consequently, only a prospective study can effectively describe the changes in the workers' health. This repeated cross-sectional study is based on a one-year investigation (spring 2020 to spring 2021) of intensive care physicians in one of the two COVID-19 hub hospitals in Central Italy. Changes in their work activity due to the pandemic were studied anonymously together with their perception of organizational justice, occupational stress, sleep quality, anxiety, depression, burnout, job satisfaction, happiness, and intention to quit. In May-June 2021, one year after the baseline, doctors reported an increased workload, isolation at work and in social life, lack of time for physical activity and meditation and compassion fatigue. Stress was inversely associated with the perception of justice in safety procedures and directly correlated with work isolation. Occupational stress was significantly associated with anxiety, depression, burnout, dissatisfaction, and intention to quit. Procedural justice was significantly associated with happiness. Doctors believed vaccinations would help control the problem; however, this positive attitude had not yet resulted in improved mental health. Doctors reported high levels of distress (73\%), sleep problems $(28 \%)$, anxiety $(25 \%)$, depression $(64 \%)$. Interventions to correct the situation are urgently needed.
\end{abstract}

Keywords: longitudinal study, emergency; infectious disease; organizational justice; stress; loneliness; compassion fatigue; meditation; prayer; insomnia; mental health; anesthetists

\section{Introduction}

Worldwide, the physical and mental health of health care workers (HCWs) has been put at risk by the pandemic of coronavirus-19 disease (COVID-19) caused by severe acute respiratory syndrome coronavirus 2 (SARS-CoV-2). During the first phase of the pandemic, HCWs who came into contact with patients and were not adequately protected developed the disease and in turn frequently became carriers of infection [1]. A systematic review of studies published before July 8, 2020, indicated that frontline HCWs frequently developed SARS-CoV-2 (estimated cumulated prevalence of a positive reverse transcription-polymerase chain reaction on mucosal swab 11\%, 95\% confidence interval (CI): 7,15$)$ [2]. In that initial period, HCWs who were COVID-19 positive accounted for a significant 
proportion of all COVID-19 patients. Although the severity and mortality of the disease were lower among HCWs [3], some were affected by long-COVID or had permanent outcomes.

Besides experiencing physical consequences, HCWs also underwent dramatic psychological pressure that manifested itself in various ways during the different phases of the pandemic. An impressive number of scientific publications (to date, over two thousand studies and more than a hundred systematic reviews and meta-analyzes) have helped us understand what happened. Each of the many cross-sectional studies focused on a specific phase in the pandemic, during which emerging problems were added to the usual stressors of medical activities, thus resulting in a high level of disorders such as post-traumatic stress, sleep problems, anxiety, depression, burnout [4]. HCWs were exposed to a wide range of emotions and environmental conditions that varied over time. In the very early stages, HCWs were mainly concerned with defining strategies to treat an unknown disease and minimize the possibility of transmission (e.g., via air conditioning systems [5] inside hospitals) or finding new safety procedures to assist patients [6]), whereas in subsequent recurring waves of the epidemic, the main stressors were prolonged periods of work in isolation, high workloads, compassion fatigue, lack of time for physical activity, meditation or relaxation.

Clearly, a cross-sectional study was not able to report this complex series of varying emotional reactions that resulted in evident repercussions on the health of the HCWs and consequently on the quality of care. Some research groups have carried out short prospective studies by repeatedly consulting HCWs anonymously to evaluate, for example, a possible reduction in stress levels between the initial phase of the pandemic and the following period $[7,8]$ or adaptation to new safety measures $[9,10]$. Studies that had a longer duration witnessed a steep drop in participation: out of the thousands contacted, only a few dozen HCWs responded during follow-up [11]. In the very extensive mental health literature concerning HCWs struggling with the pandemic, we have not been able to find longterm prospective studies that measure different aspects of mental health simultaneously.

This study, which began during the first phase of the pandemic, was designed to follow a group of workers who were continuously and exclusively engaged in the treatment of patients with COVID-19 in one of the two COVID-19 hub hospitals in Central Italy. Our aim was to measure the perception of organizational justice and occupational stress and how these varied in relation to external factors. To do this we investigated their association with possible causal factors and the resulting consequences on sleep, anxiety, depression, burnout, happiness, job satisfaction and intention to quit.

\section{Materials and Methods}

\subsection{Participants}

All the anesthetists working in the COVID-19 department of the "A. Gemelli" University hospital in Rome were invited to participate by completing an anonymous questionnaire on the SurveyMonkey online platform. The baseline collection was carried out in April-May 2020, during the first wave; a second collection was conducted in December 2020 during the second wave; the current collection was conducted in April-May 2021 during the 3rd wave, exactly one year after the first. No incentives were provided for participation. The workers were informed by email of the results of the previous surveys and asked to participate. The survey was conducted in accordance with the Helsinki Declaration. The Catholic University Ethics Committee approved the study (ID 3292).

Of the 198 eligible workers who were in service on 1 April 2021, 120 completed the present survey (participation rate $=60.6 \%$ ). The cohort varied since many workers who had participated in the baseline left the hospital in the course of the year. The percentage of trainees in the cohort increased significantly during our survey because the hospital hired them under fixed-term contracts to meet the care needs posed by the pandemic. However, the age distribution of the cohort did not change during the survey. In the current survey, participants were mainly young (70\% under 35 years of age), female (62, 
$51.7 \%)$ workers. Just over half of the participants $(65,54.2 \%)$ had been employed in the hospital for more than three years, while $15(12.5 \%)$ had been working there for less than a year.

The proportion of workers who reported unprotected exposure to COVID-19 patients increased significantly during the periods of observation (Table 1). At the time of the third survey, 59.2\% reported at least one unprotected exposure. Of these, $4.2 \%$ occurred in the non-work environment, $16.9 \%$ both in the workplace and outside the workplace, but in most cases (78.9\%) exposures were exclusively of a professional nature. 23 HCWs (19.2\%) had contracted COVID-19, and an additional 8 (6.7\%) reported having had a false-positive antigen test at the periodic screening all hospital workers undergo. A nonsignificant increase was observed in the prevalence of unprotected exposures and infections between the second and third survey. Most of the workers who had contracted the infection were completely asymptomatic $(10,38.5 \%)$ or had mild symptoms that did not require treatment $(14,53.8 \%)$; only 2 had mild symptoms that required home treatment. However, a significant proportion of the subjects who had contracted the disease reported protracted symptoms after the end of the infectious phase (long-COVID, 38.5\%) or permanent outcomes (post-COVID, 3.7\%)

Table 1. Characteristics of the population.

\begin{tabular}{cccccccc}
\hline Variables & \multicolumn{3}{c}{ Baseline } & \multicolumn{2}{c}{ 2nd survey } & \multicolumn{3}{c}{$3^{\text {rd }}$ survey } & $\mathbf{X}^{2}$ \\
& $\boldsymbol{N}$ & $\mathbf{\%}$ & $\boldsymbol{N}$ & $\mathbf{\%}$ & $\mathbf{N}$ & $\mathbf{\%}$ & $\boldsymbol{p}$ \\
\hline Participant & 154 & & 105 & & 120 & & \\
Resident & 58 & 37.7 & 55 & 52.4 & 68 & 56.7 & 0.004 \\
Gender, male & 75 & 48.7 & 51 & 48.6 & 58 & 48.3 & 0.998 \\
Age, $<35$ years & 94 & 61.0 & 76 & 72.4 & 84 & 70.0 & 0.115 \\
Reporting unprotected exposure to COVID-19 patients & 38 & 24.7 & 59 & 56.2 & 71 & 59.2 & 0.000 \\
Reporting a false-positive swab test & - & - & 2 & 1.9 & 8 & 6.7 & - \\
Reporting COVID-19 disease & - & - & 16 & 15.2 & 23 & 19.2 & 0.437 \\
Asymptomatic COVID-19 case & - & - & 6 & 37.5 & 10 & 38.5 & 0.709 \\
Mild COVID-19 case & - & - & 9 & 56.3 & 14 & 53.8 & 0.773 \\
Moderate COVID-19 case & - & - & 1 & 6.3 & 2 & 7.7 & - \\
Reporting long-COVID & - & - & - & - & 10 & 38.5 & - \\
Reporting post-COVID & - & - & - & - & 1 & 3.7 & - \\
\hline
\end{tabular}

\subsection{Questionnaire}

The questionnaire used in the survey was composed of a series of ad hoc questions, mainly related to the phase of the pandemic, and some standardized tools for measuring perceived organizational justice, stress, and effects on mental health. To facilitate the interpretation of the results, all the scales obtained from the questionnaire were standardized by dividing by the maximum value of the scale and multiplying by 100 .

Organizational justice was measured with the Italian version [12] of the Colquitt questionnaire [13-15]. The workers were invited to assess the correctness of the safety procedures by means of three-item questions (e.g., "Are these procedures error-free?"). Each question was answered according to a 5-point Likert scale, from 1 = "I totally disagree" to 5 = "I strongly agree", thus producing a scale ranging from 3 to 15. In this study, the reliability of the questionnaire, measured by Cronbach's alpha, was 0.749 (good). The raw score was standardized.

Stress was measured using the Italian version [16,17] of the Siegrist effort / reward imbalance model [18, 19]. The questionnaire contained three graded questions on a 4point Likert scale for effort and seven for the reward scale, thus constituting two scales respectively graded from 3 to 12 and 7 to 28 . Raw scores were standardized. The weighted 
ratio between effort and reward (effort reward imbalance, ERI), if greater than unity, indicates a state of distress. In this study, the reliability of the scales, measured by Cronbach's alpha, was 0.726 for Effort (good) and 0.820 for Reward (very good).

Sleep quality was measured with the 2-item version of the "Sleep Condition Indicator" (SCI-02) [20, 21], which aims to assess insomnia according to the Diagnostic Statistic Manual 5 (DSM5). Each question was graded on a 5-point Likert scale, ranging from 4 to 0 . The final score ranged between 0 and 8 , with higher values indicating better sleep quality. A score of $\leq 4$ revealed possible insomnia disorder. Cronbach's alpha in this study was 0.746 (good). Raw scores were standardized.

Mental health was measured using Goldberg's anxiety and depression scales (GADS) $[22,23]$, each of which consisted of 9 binary questions. A score of 5 or more affirmative answers to the questions on the anxiety scale, and two or more to the questions on the depression scale, respectively indicated a probable diagnosis of anxiety and depression. In this study, the reliability of the GADS questionnaire, measured by Cronbach's alpha, was 0.788 (good).

Job satisfaction was measured by a single question expressed on a 7-point Likert scale ranging from extremely dissatisfied to extremely satisfied, according to Warr et al. [24, 25]. Happiness was measured by the 10-point scale of Ab-del-Khalek [26]. The frequency of burnout feelings was measured on a 6-point scale, according to West et al. [27]. The intention to quit the hospital was measured with a single item (yes / no).

\subsection{Statistics}

The variables were analyzed in descriptive terms, mean and standard deviation for continuous variables, and frequency for categorical variables. The variables measured at baseline during the first pandemic wave $\left(\mathrm{T}_{0}\right)$, the second wave $\left(\mathrm{T}_{1}\right)$ and the third wave $\left(\mathrm{T}_{2}\right)$ were compared by analysis of variance and post-hoc comparison using the Bonferroni test if continuous, or by means of the chi-square and Fischer test if categorical.

Stepwise linear regression was used to determine which of the possible stressors had a greater effect on occupational stress. Perceived stress was the dependent variable (effort-reward imbalance). The independent variables included in the model were gender, age class, physical activity, meditation, procedural justice, workload, monotony, compassion fatigue, isolation at work, and social loneliness. In the stepwise selection method, the model started by entering the variable with the smallest $p$-value (PIN $p<0.05$ ); after each step in which a variable was added, all candidate variables in the model were checked to see if their significance had fallen below the specified tolerance level (POUT $p>0.1$ ).

To study the association of perceived justice and stress with mental health indicators, we constructed multiple linear regression models to assess the effect on sleep quality, anxiety and depression, and adjusted the result for age and gender.

Finally, we assessed the extent to which working conditions determined possible cases of anxiety, depression, burnout, dissatisfaction and intention to leave the workplace by constructing multiple logistic regression models adjusted for gender and age. In this way we calculated the odds ratio (OR). For each OR we calculated the $95 \%$ confidence interval (CI95\%). USA).

Analyses were performed using IBM/SPSS 26.0 (IBM Corporation, Armonk, NY,

\section{Results}

In the third survey, workers confirmed that their workload was greater/much greater than before the pandemic. For many of them, the type of medical activity had also become progressively more repetitive and monotonous because of the need to continually apply the same diagnostic and therapeutic procedures in COVID-19 patients. For safety reasons, contact with their patients' families was limited and there was an increasingly frequent need to inform patients of the unfavourable outcome of treatment; all of which contributed to determining compassion fatigue (Table 2). All these unfavourable occupational 
changes were reported more frequently in this survey than at baseline. Moreover, $40 \%$ of workers complained of having to work in isolation and about $70 \%$ suffered from a reduction in social contacts. However, between the second and third surveys we observed a significantly lower frequency of workers who complained of isolation in social life. Factors that can contribute to increasing resilience such as the time devoted to physical activity, meditation, prayer or spiritual activities were reduced or greatly reduced in most workers, as in previous surveys (Table 2).

Table 2. Changes reported during the COVID-19 outbreak and prevalence of high stress, insomnia, anxiety, and depression during the 1 st and 2 nd waves.

\begin{tabular}{|c|c|c|c|c|c|c|c|}
\hline \multirow{2}{*}{ Reported Effect } & \multicolumn{2}{|c|}{ Baseline } & \multicolumn{2}{|c|}{ 2nd survey } & \multicolumn{3}{|c|}{ 3rd survey } \\
\hline & $N$ & $\%$ & $N$ & $\%$ & $N$ & $\%$ & $p$ \\
\hline Increased/greatly increased workload & 77 & 50.0 & 83 & 83.0 & 98 & 84.5 & 0.000 \\
\hline The work became more repetitive and monotonous & 51 & 33.1 & 36 & 36.0 & 53 & 45.7 & 0.162 \\
\hline $\begin{array}{c}\text { More frequent need to inform of the death of a } \\
\text { relative }\end{array}$ & 61 & 39.6 & 65 & 65.0 & 81 & 69.8 & 0.000 \\
\hline Isolation at work & & & 42 & 42.0 & 47 & 40.5 & 0.669 \\
\hline Isolation in life & & & 81 & 81.0 & 78 & 67.2 & 0.008 \\
\hline Time for physical exercise was shorter/much shorter & 117 & 76.0 & 80 & 80.0 & 92 & 79.3 & 0.742 \\
\hline Time for meditation was shorter/much shorter & 72 & 46.8 & 65 & 65.0 & 74 & 63.8 & 0.006 \\
\hline Distressed (effort/reward weighted ratio >1) & 117 & 76.0 & 80 & 80.0 & 83 & 72.8 & 0.468 \\
\hline Insomniac (SCI08 score $\leq 16$; SCI02 score $\leq 4$ ) & 58 & 43.3 & 33 & 33.0 & 32 & 28.1 & 0.037 \\
\hline Anxious (GADS anxiety score $\geq 5$ ) & 40 & 26.0 & 31 & 31.0 & 29 & 25.4 & 0.599 \\
\hline Depressed (GADS depression score $\geq 2$ ) & 75 & 48.7 & 63 & 63.0 & 73 & 64.0 & 0.017 \\
\hline
\end{tabular}

SCI08 = Sleep Condition Indicator, used in the baseline survey; SCI02 = Sleep Condition Indicator, short form, two items; used in the $2^{\text {nd }}$ and $3^{\text {rd }}$ survey; GADS = Goldberg

All workers were vaccinated between the second and third surveys. Most of them were moderately or strongly in agreement (71.0\%) with the following statement: "With vaccinations it will be possible to control the pandemic".

The perception of procedural justice, i.e., the degree of trust in safety measures, was not high, exactly as in the previous surveys (Table 3).

Table 3. Mental health indicators (perceived justice, occupational stress, sleep quality, anxiety, depression) in anesthesiologists during the three waves of the COVID-19 outbreak.

\begin{tabular}{|c|c|c|c|c|c|c|}
\hline Variable & $\begin{array}{c}\text { 1st Wave } \\
\text { Mean } \pm \text { s.d. }\end{array}$ & $\begin{array}{l}\text { 2nd Wave } \\
\text { Mean } \pm \text { s.d. }\end{array}$ & $\begin{array}{l}\text { 3nd Wave } \\
\text { Mean } \pm \text { s.d. }\end{array}$ & $\begin{array}{c}\text { ANOVA } \\
p\end{array}$ & \multicolumn{2}{|c|}{$\begin{array}{c}\text { Bonferroni } \\
p\end{array}$} \\
\hline Procedural Justice & $49.91 \pm 13.64$ & $53.60 \pm 15.60$ & $53.33 \pm 15.67$ & 0.079 & & \\
\hline Effort & $71.48 \pm 16.59$ & $77.91 \pm 14.03$ & $77.34 \pm 14.52$ & 0.001 & $\begin{array}{c}1 \text { vs. } 2 \\
0.003\end{array}$ & $\begin{array}{l}1 \text { vs.3 } \\
0.006\end{array}$ \\
\hline Reward & $58.88 \pm 13.13$ & $59.36 \pm 13.95$ & $61.40 \pm 13.97$ & 0.304 & & \\
\hline Job stress & $1.30 \pm 0.51$ & $1.42 \pm 0.56$ & $1.37 \pm 0.57$ & 0.228 & & \\
\hline Sleep quality & $59.64 \pm 25.11$ & $65.13 \pm 28.50$ & $67.43 \pm 27.31$ & 0.051 & & \\
\hline Anxiety & $3.04 \pm 2.32$ & $3.34 \pm 2.33$ & $3.02 \pm 1.93$ & 0.487 & & \\
\hline Depression & $1.97 \pm 1.87$ & $2.71 \pm 1.95$ & $2.49 \pm 1.91$ & 0.007 & $\begin{array}{c}1 \text { vs. } 2 \\
0.008\end{array}$ & $\begin{array}{c}1 \text { vs.3 } \\
\text { n.s. }\end{array}$ \\
\hline
\end{tabular}

On average, the efforts made by workers to respond to job demands remained very high $(77 \%$ of the maximum value), confirming the level recorded in the second survey, which was significantly higher than at baseline. The rewards earned from work showed a modest, non-significant increase. Occupational stress levels were on average much higher than the equivalence level between efforts and rewards, indicating a widespread state of distress in the sample. The share of distressed workers remained constant in the 
three surveys: at least three out of four workers were in a state of distress throughout the year.

The average score of the GADS anxiety scale did not register significant changes in the third survey, and therefore it was confirmed that more than one in four workers had a score corresponding to a diagnosis of anxiety made by a specialist. Conversely, the mean score of the depression scale showed a significant increase in the second survey compared to the baseline, and in the present survey it remained constant. Three out of five workers manifested depressive symptoms.

The quality of sleep, while remaining rather low (scores on average at two thirds of the maximum) showed a slight, non-significant improvement in the third survey compared to the baseline. The number of workers affected by insomnia was significantly lower in this survey than during the first wave.

A stepwise linear regression analysis was conducted to evaluate which of the variations in work activity associated with COVID-19 was most closely related to occupational stress. The prediction model, which explained $39.4 \%$ of the variance of stress, included isolation at work and a reduced perception of organizational justice, in addition to age group $>35$ years (Table 4 ).

Table 4. Third wave. Stepwise linear regression analysis. Relationship between job changes and perceived work-related stress (ERI).

\begin{tabular}{ccc}
\hline Variable & \multicolumn{2}{c}{ ERI } \\
\cline { 2 - 3 } & Standardized Beta & $p$ \\
\hline Isolation at work & 0.383 & 0.000 \\
Procedural Justice & -0.335 & 0.000 \\
Age class. & 0.293 & 0.000 \\
\hline Determination coefficient of the model $\left(\mathrm{R}^{2}\right)$ & 0.394 \\
\hline
\end{tabular}

Variables excluded from the model: gender, monotony, compassion fatigue, social loneliness, physical activity, workload, and meditation.

The perception of organizational justice and the occupational stress variables were significantly associated with poor sleep quality, anxiety, and depression. In particular, the effort made to work was significantly associated with a reduced quality of sleep and with an increased anxiety and depression score in a multiple linear regression model adjusted for demographic variables (Table 5).

Table 5. Third wave. Health outcomes associated with procedural justice and occupational stress. Linear regression analysis adjusted for age and gender.

\begin{tabular}{|c|c|c|c|c|c|c|}
\hline \multirow{2}{*}{ Variable } & \multicolumn{2}{|c|}{ Sleep Quality } & \multicolumn{2}{|l|}{ Anxiety } & \multicolumn{2}{|l|}{ Depression } \\
\hline & Standardized Beta & $p$ & Standardized Beta & $p$ & Standardized Beta & $p$ \\
\hline Procedural justice & 0.062 & 0.628 & -0.022 & 0.845 & 0.027 & 0.810 \\
\hline Effort & -0.333 & 0.013 & 0.541 & 0.000 & 0.578 & 0.000 \\
\hline Reward & 0.066 & 0.613 & -0.084 & 0.473 & -0.057 & 0.622 \\
\hline
\end{tabular}

Twenty-one percent of workers said they were dissatisfied with their job and $41.2 \%$ said they intended to quit. The average happiness score was $6.55 \pm 1.92$ on a scale of 1 to 10 . Nearly half the workers $(46.5 \%)$ reported experiencing burnout several times a month, or more frequently.

The relationship between stress and the perception of justice and mental health was studied using logistic regression analysis. The risk of being anxious and depressed or suffering from burnout was significantly associated with effort, while the intangible rewards derived from work (reward) were protective towards burnout, job dissatisfaction and in- 
tention to quit. Dissatisfaction with one's job and the intention to leave the job were significantly associated with high effort and low reward. Happiness was significantly associated with organizational justice (Table 6).

Table 6. Third wave. Health outcomes associated with procedural justice and occupational stress. Multivariate logistic regression model adjusted for age and gender.

\begin{tabular}{|c|c|c|c|c|c|c|}
\hline \multirow{3}{*}{ Predictor } & \multicolumn{6}{|c|}{ Dependent variable } \\
\hline & \multicolumn{6}{|c|}{ OR (CI95\%) } \\
\hline & Anxious ${ }^{1}$ & Depressed $^{2}$ & Burned-out ${ }^{3}$ & Dissatisfied $^{4}$ & Happy $^{3}$ & Intention to quit \\
\hline Procedural justice & $(0.843-1.340)$ & $(0.729-1.124)$ & $(0.840-1.344)$ & $(0.765-1.230)$ & $(1.000-1.568)$ & $(0.675-1.121)$ \\
\hline \multirow{2}{*}{ Effort } & 1.721 & 1.515 & 2.151 & 1.459 & 0.765 & 1.871 \\
\hline & $(1.199-2.468)^{* *}$ & $(1.095-2.096)^{*}$ & $(1.435-3.224)^{* * *}$ & $(1.027-2.071)^{*}$ & $(0.560-1.044)$ & $(1.230-2.847)^{* *}$ \\
\hline Reward & $(0.825-1.087)$ & $(0.812-1.057)$ & $(0.737-0.975)^{*}$ & $(0.655-0.894)^{* * *}$ & $(0.916-1.201)$ & $(0.650-0.892)^{* * *}$ \\
\hline
\end{tabular}

Notes: 1 = GADS anxiety score $\geq 5 ; 2$ = GADS depression score $\geq 2 ; 3=$ dichotomized at the median; 4 = moderately, very, or extremely dissatisfied. ${ }^{*}=\mathrm{p}<0.05 ;{ }^{* *}=\mathrm{p}<0.01 ;{ }^{* * *}=\mathrm{p}<0.001$

\section{Discussion}

This study, which, to the best of our knowledge, is the only prospective research on HCWs caring exclusively for COVID-19 cases conducted over a period of one year starting from the beginning of the pandemic, has shown that the mental health status of these workers is not excellent. Occupational stress, which remained high throughout the observation period, was associated with an elevated frequency of anxiety and an increasing prevalence of depression. Nearly half of workers often felt burnout, and levels of job satisfaction and happiness in life were not satisfactory. A considerable number of HCWs planned to leave the hospital.

All the effects observed in our sample have been reported by other cross-sectional studies on HCWs engaged on the frontline during the pandemic. Insomnia, anxiety and depression were observed in the early phases of the pandemic in Chinese workers [28]. Fear and lack of confidence in safety measures were associated with reduced job satisfaction and intention to leave the job [29]. Later on these negative emotions sometimes led to post-traumatic stress disorder $[30,31]$ or burnout $[32,33]$. The psychological picture naturally varied over time; a few months after the acute phase of the epidemic, both recurring involuntary memories and happiness were described [34]. The type of occupational problems to which workers were exposed changed over the course of the pandemic: in the early stages, lack of readiness, a shortage of PPE, separation from families, stigma [35], and an increased workload [36,37] prevailed among professionals, whereas in later stages, other stressors such as the death of patients and colleagues inducing moral injury and distress [38, 39], isolation or lack of support at work [40,41] attracted the attention of researchers. Moreover, lack of physical activity has been associated with poor quality of life in frontline HCWs [42], and a number of studies have underlined the importance of meditation and spirituality in improving psychological resilience in HCWs during the pandemic [43-46].

The repeated cross-sectional nature of our epidemiological design enabled us to follow variations over time in the response of HCWs to the pressure posed by the pandemic. Our setting - one of the two hub hospitals for COVID-19 in Central Italy - was typical of the conditions observed throughout the country. During the first wave of the pandemic in Italy in the spring of 2020 [47], the shortage of personal protective equipment (PPE), the fear of infection and uncertainty about new safety measures were the main stressors [48], especially for younger workers and residents [49]. Before widespread screening measures were introduced [50], the oligosymptomatic carriers of SARS-CoV2 represented a particularly threatening occupational risk that was difficult to predict [51]. HCWs who experienced unprotected exposure to patients with Covid-19 and, to a greater extent, those who 
tested positive for PCR, manifested elevated levels of anxiety, depression, and sleep disturbances [52]. Our prospective observation of a highly selected sample of workers continuously engaged in caring for COVID-19 patients, demonstrated that in the first phase of the pandemic, the main stressors were the need to adhere to new safety procedures and uncertainty about their effectiveness [53]. The younger and less experienced residents complained of a significantly lower level of informational justice than the specialists, although they had all undergone the same training [49]. Confidence in the correctness of safety procedures immediately proved to be an important factor in protecting against occupational stress. The widespread state of alarm and fear for their own health and that of their family members strongly influenced the quality of sleep [53].

During the second wave, in the autumn of 2020 [54], when the question of protective devices had been solved and new safety procedures were in place, other problems became evident. Difficulties in relations between doctors and patients' relatives led to a sharp deterioration in public opinion towards doctors, as witnessed by a surge in complaints of malpractice [55]. The availability of effective and rapid screening tests made possible better control of infections, which however continued to affect HCWs, thus reducing the workforce even in sectors where workload was already excessive. The isolation of patients from their relatives and the isolation of the HCWs from their colleagues proved to be a major stressor. The frontline HCWs have also been strongly isolated in social life and have registered a strong change in the orientation of public opinion towards them, which has passed in a few months from very favourable to critical [56]. In our sample, the high workload and lack of time for meditation and activities that allow for mental recovery have been, in doctors' opinion, increasingly important stressors. Their work was always carried out in solitude. The relationships with the patients' relatives became less, while paradoxically the need to inform them of the unfavorable outcome of the therapies increased. This has certainly contributed to changing opinion towards doctors and has increased their social isolation. The prolongation of the epidemic, with workload levels that were higher than at baseline, without time to devote to family, sports, meditation, and persistent uncertainty about the correctness and effectiveness of safety procedures, has led to a significant increase in symptoms of depression [56].

In early 2021, the availability of vaccines made it possible to vaccinate all HCWs who consequently perceived the possibility of controlling the pandemic. Immunized workers probably felt able to resume social activities. In fact, the 3rd survey reported a reduced prevalence of those who complained of isolation in life. However, at the time of our investigation, these positive changes had still not had a significant impact on mental health conditions. Only sleep quality showed a modest improvement from baseline, while distress, anxiety and depression remained unacceptably high. Nevertheless, the trend towards improved sleep is worth highlighting because sleep has been shown to be a moderator of the relationship between stress and mental health [52] and could therefore be a positive indication of possible future health improvements. The factors that weigh most heavily on the perception of stress at this moment are isolation at work and the perception of a lack of correctness in the organization of work. A year after the outbreak of the coronavirus epidemic, older workers, such as specialists with permanent contracts, are shouldering the greatest burden, probably because during the current stable phase of the epidemic, they are responsible for organization and training.

Clearly, the situation illustrated in our study calls for preventive and supportive action. Unfortunately, it is far from easy to implement this kind of intervention. The excessive workload could be remedied by increasing staff, but adequately trained personnel are not available and, as we have seen, the hiring of young physicians leads to training problems. Preventive social distancing hinders clinical training and relationships with patients' relatives, thus increasing clinical risk and the danger of a reduction in the quality of care. Lack of time to devote to physical activity or meditation and intellectual activities reduces resilience and hinders the application of individual psychological support treatments. The high percentage of workers reporting unprotected exposures and the fact that one in five has contracted COVID-19 indicate the need to improve safety procedures and 
their enforcement. The pandemic has compelled hospital authorities to introduce safety measures with a "top-down" approach. The low degree of confidence in these procedures, which still persists a year after their implementation, should encourage the authorities to obtain greater worker participation in the planning and control of these measures. A "bottom-up" approach involving participatory ergonomics groups [57] could increase the collaboration of workers, the effectiveness of measures and the perception of organizational justice, thus reducing occupational stress. Another administrative measure that could reduce the perception of stress (if not effort) would be to increase material and immaterial rewards that doctors receive for their work. Furthermore, given the importance of sleep in the relationship between stress and pathologies $[58,59]$, the utmost attention should be given to scheduling work shifts and respecting recovery times. Workers should be informed about the importance of proper sleep hygiene and trained to prevent sleep disturbances. This simple measure has proved effective in preventing stress damage in other categories of workers [60].

This study has several limitations. Although it was conducted over a one-year period on a selected group of doctors who were always exposed to a specific risk and the survey simultaneously investigated numerous variables that make up the complex relationships between work, stress and health, our study was limited by being able to observe only one setting and therefore a numerically modest sample. Because participants were guaranteed anonymity, we were unable to evaluate the incidence of the reported pathologies; however, the prospective nature of the observations, which were repeated in correspondence with the three pandemic waves, made it possible to describe the evolution of the psychological state of frontline physicians during COVID-19 with greater effectiveness than in the numerous cross-sectional investigations conducted around the world.

In conclusion, our study documented the complexity and relevance of the psychological response of physicians at the forefront of the COVID19 pandemic. The picture that emerged from one year of observations calls for the adoption of support measures. If the photo symbolizing healthcare in Italy in the spring of 2020 was that of a nurse falling asleep in the workplace [61], thus illustrating both the self-denial of the individual and the inadequacy of work organization, today it is fair to ask that doctors who provide intensive care for COVID-19 patients have full occupational well-being.

Author Contributions: Conceptualization, N.M. and P.M.S.; methodology, N.M.; formal analysis, N.M.; investigation, P.M.S.; resources, N.M.; data curation, N.M.; writing - original draft preparation, N.M.; writing - review and editing, N.M.; supervision, M.A. All authors have read and agreed to the published version of the manuscript.

Funding: This research received no external funding.

Institutional Review Board Statement: The study was conducted according to the guidelines of the Declaration of Helsinki and approved by the Ethics Committee of the Università Cattolica del Sacro Cuore, Fondazione Policlinico Agostino Gemelli IRCCS, Roma, protocol code 3292, approved $30 / 9 / 2020$.

Informed Consent Statement: Informed consent was obtained from all subjects involved in the study.

Data Availability Statement: Data deposited on Zenodo:

Acknowledgments: We thank all the participants who kindly responded to the survey. We also thank E.A. Wright, who revised the English language.

Conflicts of Interest: The authors declare no conflict of interest.

\section{References}

1. Chirico, F.; Nucera, G.; Magnavita, N. COVID-19: Protecting Healthcare Workers is a priority. Infect. Control Hosp. Epidemiol. 2020, 41, 1117, doi:10.1017/ice.2020.148.

2. Gómez-Ochoa, S.A.; Franco, O.H.; Rojas, L.Z.; Raguindin, P.F.; Roa-Díaz, Z.M.; Wyssmann, B.M.; Guevara, S.L.R.; Echeverría, L.E.; Glisic, M.; Muka, T. COVID-19 in Health-Care Workers: A Living 
Systematic Review and Meta-Analysis of Prevalence, Risk Factors, Clinical Characteristics, and Outcomes. Am J Epidemiol. 2021;190(1):161-175. doi: 10.1093/aje/kwaa191.

3. Sahu, A.K.; Amrithanand, V.T.; Mathew, R.; Aggarwal, P.; Nayer, J.; Bhoi, S. COVID-19 in health care workers - A systematic review and meta-analysis. Am J Emerg Med. 2020;38(9):1727-1731. doi: 10.1016/j.ajem.2020.05.113.

4. Chirico, F.; Nucera, G.; Magnavita, N. Protecting the mental health of healthcare workers during the COVID-19 emergency. (Editorial). Brit. J. Psych. Int. 2020, doi:10.1192/bji.2020.39.

5. Chirico, F.; Sacco, A.; Bragazzi, N.L.; Magnavita, N. Can Air-Conditioning Systems Contribute to the Spread of SARS/MERS/COVID-19 Infection? Insights from a Rapid Review of the Literature. Int J Environ Res Public Health. 2020;17(17):6052. doi: 10.3390/ijerph17176052.

6. Magnavita, N.; Sacco, A.; Nucera, G.; Chirico, F. First aid during the Covid-19 pandemic. (Editorial). Occup Med (Lond). 2020;70(7):458-460. doi: 10.1093/occmed/kqaa148.

7. Chew, Q.H.; Chia, F.L.; Ng, W.K.; Lee, W.C.I.; Tan, P.L.L.; Wong, C.S.; Puah, S.H.; Shelat, V.G.; Seah, E.D.; Huey, C.W.T.; et al. Perceived Stress, Stigma, Traumatic Stress Levels and Coping Responses amongst Residents in Training across Multiple Specialties during COVID-19 Pandemic-A Longitudinal Study. Int. J. Environ. Res. Public Health 2020, 17, 6572, doi:10.3390/ijerph17186572.

8. Cai, Z.; Cui, Q.; Liu, Z.; Li, J.; Gong, X.; Liu, J.; Wan, Z.; Yuan, X.; Li, X.; Chen, C.; et al. Nurses endured high risks of psychological problems under the epidemic of COVID-19 in a longitudinal study in Wuhan China. J. Psychiatr. Res. 2020, 131, 132-137, doi:10.1016/j.jpsychires.2020.09.007.

9. Olivieri, J.G.; de España, C.; Encinas, M.; Ruiz, X.F.; Miró, Q.; Ortega-Martinez, J.; Durán-Sindreu, F. General Anxiety in Dental Staff and Hemodynamic Changes over Endodontists' Workday during the Coronavirus Disease 2019 Pandemic: A Prospective Longitudinal Study. J. Endod. 2021, 47, 196203, doi:10.1016/j.joen.2020.10.023.

10. Baumann, B.M.; Cooper, R.J.; Medak, A.J.; Lim, S.; Chinnock, B.; Frazier, R.; Roberts, B.W.; Epel, E.S.; Rodriguez, R.M. Emergency physician stressors, concerns, and behavioral changes during COVID-19: A longitudinal study. Acad. Emerg. Med. 2021, 28, 314-324, doi:10.1111/acem.14219.

11. Sasaki, N.; Kuroda, R.; Tsuno, K.; Kawakami, N. The deterioration of mental health among healthcare workers during the COVID-19 outbreak: A population-based cohort study of workers in Japan. Scand. J. Work Environ. Health 2020, 46, 639-644, doi:10.5271/sjweh.3922.

12. Magnavita, N.; Bergamaschi, A. Justice at the workplace. Validation of the Italian version of Colquitt's justice measurement questionnaire (JM20). G. Ital. Med. Lav. Ergon. 2008, 30 (Suppl. 2), 449-450.

13. Elovainio, M.; Heponiemi, T.; Sinervo, T.; Magnavita, N. Organizational justice and health; review of evidence. G. Ital. Med. Lav. Ergon. 2010, 32, B5-B9.

14. Colquitt, J.A. On the dimensionality of organizational justice: A construct validation of a measure. J. Appl. Psychol. 2001, 86, 386-400.

15. Elovainio, M.; Heponiemi, T.; Kuusio, H.; Sinervo, T.; Hintsa, T.; Aalto, A.M. Developing a short measure of organizational justice: A multisample health professionals study. J. Occup. Environ. Med. 2010, 52, 1068-1074, doi:10.1097/JOM.0b013e3181f8447c.

16. Magnavita, N.; Garbarino, S.; Siegrist, J. The use of parsimonious questionnaires in occupational health surveillance. Psychometric properties of the short Italian version of the Effort/Reward Imbalance questionnaire. TSWJ Sci. World J. 2012, 2012, 372852, doi:10.1100/2012/372852.

17. Magnavita N. Two tools for health surveillance of job stress: The Karasek Job Content Questionnaire and the Siegrist Effort Reward Imbalance Questionnaire. G Ital Med Lav Ergon 2007; 29 (3): 667-670

18. Siegrist, J. Adverse health effects of high-effort/low-reward conditions. J. Occup. Health Psychol. 1996, $1,27-41$.

19. Siegrist, J.; Wege, N.; Puhlhofer, F.; Wahrendorf, M. A short generic measure of work stress in the era of globalization: Effort-reward imbalance. Int. Arch. Occup. Environ. Health 2009, 82, 1005-1013.

20. Espie, C.A.; Kyle, S.D.; Hames, P.; Gardani, M.; Fleming, L.; Cape, J. The Sleep Condition Indicator: A clinical screening tool to evaluate insomnia disorder. BMJ Open 2014, 4, e004183, doi:10.1136/bmjopen-2013-004183.

21. Palagini, L.; Ragno, G.; Caccavale, L.; Gronchi, A.; Terzaghi, M.; Mauri, M.; Kyle, S.; Espie, C.A.; Manni, A. Italian validation of the Sleep Condition Indicator: A clinical screening tool to evaluate Insomnia Disorder according to DSM-5 criteria. Int. J. Psychophysiol. 2015, 98 Pt 1, 435-440, doi:10.1016/j.ijpsycho.2015.08.008.

22. Goldberg, D.; Bridges, K.; Duncan-Jones, P.; Grayson, D. Detecting anxiety and depression in general medical settings. BMJ 1988, 297, 897-899.

23. Magnavita, N. Anxiety and depression at work. The A/D Goldberg Questionnaire. G. Ital. Med. Lav. Ergon. 2007, 29, 670-671.

24. Warr, P.; Cook, J.; Wall, T. Scales for the measurement of some work attitudes and aspects of psychological well-being. J. Occup, Psychol. 1979, 52, 129-148. 
25. Magnavita, N.; Fileni, A.; Magnavita, L.; Mammi, F.; Roccia, K.; De Matteis, B.; Colozza, V.; Vitale, M.R. Job satisfaction. Use of the Job Satisfaction Scale (JSS). G Ital Med Lav Ergon 2007; 29 (3): 655657.

26. Abdel-Khalek, A.M. Measuring happiness with a single-item scale. Soc. Behav. Personal. 2006, 34, 139-150, doi:10.2224/sbp.2006.34.2.139.

27. West, C.P.; Dyrbye, L.N.; Satele, D.V.; Sloan, J.A.; Shanafelt, T.D. Concurrent validity of single-item measures of emotional exhaustion and depersonalization in burnout assessment. J. Gen. Intern. Med. 2012, 27, 1445-1452, doi:10.1007/s11606-012-2015-7.

28. Lai, J.; Ma, S.; Wang, Y.; Lai, J.; Ma, S.; Wang, Y.; Cai, Z.; Hu, J.; Wei, N.; Wu, J.; et al. Factors associated with mental health outcomes among health care workers exposed to coronavirus disease 2019. JAMA Netw. Open 2020, 3, e203976.

29. Labrague, L.J.; de Los Santos, J.A.A. Fear of COVID-19, psychological distress, work satisfaction and turnover intention among frontline nurses. J. Nurs. Manag. 2021, 29, 395-403, doi:10.1111/jonm.13168.

30. Lu, M.Y.; Ahorsu, D.K.; Kukreti, S.; Strong, C.; Lin, Y.H.; Kuo, Y.J.; Chen, Y.P.; Lin, C.Y.; Chen, P.L.; Ko, N.Y.; Ko, W.C. The Prevalence of Post-traumatic Stress Disorder Symptoms, Sleep Problems, and Psychological Distress Among COVID-19 Frontline Healthcare Workers in Taiwan. Front Psychiatry. 2021; 12:705657. doi: 10.3389/fpsyt.2021.705657.

31. Sanghera, J.; Pattani, N.; Hashmi, Y.; Varley, K.F.; Cheruvu, M.S.; Bradley, A.; Burke, J.R. The impact of SARS-CoV-2 on the mental health of healthcare workers in a hospital setting-A Systematic Review. J Occup Health. 2020;62(1):e12175. doi: 10.1002/1348-9585.12175.

32. Miguel-Puga, J.A.; Cooper-Bribiesca, D.; Avelar-Garnica, F.J.; Sanchez-Hurtado, L.A.; Colin-Martínez, T.; Espinosa-Poblano, E.; Anda-Garay, J.C.; González-Díaz, J.I.; Segura-Santos, O.B.; Vital-Arriaga, L.C.; Jáuregui-Renaud, K. Burnout, depersonalization, and anxiety contribute to post-traumatic stress in frontline health workers at COVID-19 patient care, a follow-up study. Brain Behav. 2021;11(3):e02007. doi: 10.1002/brb3.2007.

33. Magnavita, N.; Chirico, F.; Garbarino, S.; Bragazzi, N.L.; Santacroce, E.; Zaffina, S. SARS/MERS/SARS-CoV-2 Outbreaks and Burnout Syndrome among Healthcare Workers. An Umbrella Systematic Review. Int. J. Environ. Res. Public Health 2021, 18, 4361, doi:10.3390/ijerph18084361.

34. Zhang, X.; Sheng, Q.; Wang, X.; Cai, C. The experience of frontline nurses four months after COVID19 rescue task in China: A qualitative study. Arch Psychiatr Nurs. 2021 ;35(4):358-363. doi: 10.1016/j.apnu.2021.05.007.

35. Nyashanu, M.; Pfende, F.; Ekpenyong, M. Exploring the challenges faced by frontline workers in health and social care amid the COVID-19 pandemic: experiences of frontline workers in the English Midlands region, UK. J Interprof Care. 2020;34(5):655-661. doi: 10.1080/13561820.2020.1792425

36. Chen, J.; Liu, X.; Wang, D.; Jin, Y.; He, M.; Ma, Y.; Zhao, X.; Song, S.; Zhang, L.; Xiang, X.; Yang, L.; Song, J.; Bai, T.; Hou, X. Risk factors for depression and anxiety in healthcare workers deployed during the COVID-19 outbreak in China. Soc Psychiatry Psychiatr Epidemiol. 2021;56(1):47-55. doi: 10.1007/s00127-020-01954-1.

37. Brophy, J.T.; Keith, M.M.; Hurley, M.; McArthur, J.E.. Sacrificed: Ontario Healthcare Workers in the Time of COVID-19. New Solut. 2021;30(4):267-281. doi: 10.1177/1048291120974358.

38. Chersich, M.F.; Gray, G.; Fairlie, L.; Eichbaum, Q.; Mayhew, S.; Allwood, B.; English, R.; Scorgie, F.; Luchters, S.; Simpson, G.; Haghighi, M.M.; Pham, M.D.; Rees, H. COVID-19 in Africa: care and protection for frontline healthcare workers. Global Health. 2020;16(1):46. doi: 10.1186/s12992-020-005743.

39. Selman, L.E.; Chao, D.; Sowden, R.; Marshall, S.; Chamberlain, C.; Koffman, J. Bereavement Support on the Frontline of COVID-19: Recommendations for Hospital Clinicians. J Pain Symptom Manage. 2020;60(2):e81-e86. doi: 10.1016/j.jpainsymman.2020.04.024.

40. Marvaldi, M.; Mallet, J.; Dubertret, C.; Moro, M.R.; Guessoum, S.B. Anxiety, depression, traumarelated, and sleep disorders among healthcare workers during the COVID-19 pandemic: A systematic review and meta-analysis. Neurosci. Biobehav. Rev. 2021, 126, 252-264, doi:10.1016/j.neubiorev.2021.03.024.

41. Cabarkapa, S.; Nadjidai, S.E.; Murgier, J.; Ng, C.H. The psychological impact of COVID-19 and other viral epidemics on frontline healthcare workers and ways to address it: A rapid systematic review. Brain Behav. Immun. Health 2020, 100144, doi:10.1016/j.bbih.2020.100144.

42. Zhang, L.; Ji, R.; Ji, Y.; Liu, M.; Wang, R.; Xu, C. Relationship Between Acute Stress Responses and Quality of Life in Chinese Health Care Workers During the COVID-19 Outbreak. Front Psychol. 2021; 12:599136. doi: 10.3389/fpsyg.2021.599136.

43. Lai, K.S.P.; Watt, C.; Ionson, E.; Baruss, I.; Forchuk, C.; Sukhera, J.; Burhan, A.M.; Vasudev, A. Breath Regulation and yogic Exercise An online Therapy for calm and Happiness (BREATH) for frontline hospital and long-term care home staff managing the COVID-19 pandemic: A structured summary 
of a study protocol for a feasibility study for a randomised controlled trial. Trials 2020, 21, 648, doi:10.1186/s13063-020-04583-w.

44. Ribeiro, M.R.C.; Damiano, R.F.; Marujo, R.; Nasri, F.; Lucchetti, G. The role of spirituality in the COVID-19 pandemic: a spiritual hotline project. J Public Health (Oxf). 2020;42(4):855-856. doi: 10.1093/pubmed/fdaa120.

45. Feng, Z.; Xu, L.; Cheng, P.; Zhang, L.; Li, L.J.; Li, W.H. The psychological impact of COVID-19 on the families of first-line rescuers. Indian J Psychiatry. 2020;62(Suppl 3):S438-S444. doi: 10.4103/psychiatry.IndianJPsychiatry_1057_20.

46. Sarmiento, P.J.D. Wounded healers: a call for spiritual care towards healthcare professionals in time of COVID-19 pandemic. J Public Health (Oxf). 2021;43(2):e273-e274. doi: 10.1093/pubmed/fdaa232.

47. Magnavita, N.; Sacco, A.; Chirico, F. Covid-19 pandemic in Italy: Pros and cons. ZNOZ Zdrowie Publiczne $i$ Zarzadzanie 2020, 18, doi:10.4467/20842627OZ.20.002.12656. Available online: https://www.ejournals.eu/Zdrowie-Publiczne-i-Zarzadzanie/202/Tom-18-zeszyt-1/art/17398/ (accessed on 20 February 2021).

48. Cag, Y.; Erdem, H.; Gormez, A.; Ankarali, H.; Hargreaves, S.; Ferreira-Coimbra, J.; Rubulotta, F.; Belliato, M.; Berger-Estilita, J.; Pelosi, P.; Blot, S.; Lefrant, J.Y.; Mardani, M.; Darazam, I.A.; Cag, Y.; Rello, J. Anxiety among front-line health-care workers supporting patients with COVID-19: A global survey. Gen Hosp Psychiatry. 2021; 68:90-96. doi: 10.1016/j.genhosppsych.2020.12.010.

49. Magnavita, N.; Soave, P.M.; Antonelli, M. Teaching safety - Resident anaesthetists at the forefront of COVID-19. Industrial Health, 2021; 59, ahead-of-print. Available in: Zenodo. DOI: 10.5281/zenodo. 5035431

50. Chirico, F.; Nucera, G.; Magnavita, N. Hospital infection and COVID-19: Do not put all your eggs on the "swab" tests. Infect Control Hosp Epidemiol. 2021;42(3):372-373. doi: 10.1017/ice.2020.254

51. Chirico, F.; Magnavita, N. The Crucial Role of Occupational Health Surveillance for Health-care Workers During the COVID-19 Pandemic. Workplace Health Saf. 2021;69(1):5-6. doi: $10.1177 / 2165079920950161$.

52. Magnavita, N.; Tripepi, G.; Di Prinzio, R.R. Symptoms in Health Care Workers during the COVID19 Epidemic. A Cross-Sectional Survey. Int. J. Environ. Res. Public Health 2020, 17, 5218, doi:10.3390/ijerph17145218.

53. Magnavita, N.; Soave, P.M.; Ricciardi, W.; Antonelli, M. Occupational stress and mental health of anaesthetists during the COVID-19 pandemic. Int. J. Environ. Res. Public Health 2020, 17, 8245, doi:10.3390/ijerph17218245.

54. Chirico, F.; Sacco, A.; Nucera, G.; Magnavita, N. Coronavirus disease 2019: The second wave in Italy. JHR J. Health Res. 2021, ahead-of-print, doi:10.1108/JHR-10-2020-0514.

55. Magnavita, N.; Chirico, F.; Sacco, A. Covid-19, from hospitals to courts. The Lancet 2021, Published Online April 14, 2021. doi:10.1016/S0140-6736(21)00678-4.

56. Magnavita, N.; Soave, P.M.; Antonelli, M. Prolonged Stress Causes Depression in Frontline Workers Facing the COVID-19 Pandemic-A Repeated Cross-Sectional Study in a COVID-19 Hub-Hospital in Central Italy. Int J Environ Res Public Health. 2021;18(14):7316. doi: 10.3390/ijerph18147316.

57. Magnavita, N. Medical Surveillance, Continuous Health Promotion and a Participatory Intervention in a Small Company. Int J Environ Res Public Health. 2018;15(4). pii: E662. doi: 10.3390/ijerph15040662

58. Magnavita, N.; Garbarino, S. Sleep, Health and Wellness at Work: A Scoping Review. Int J Environ Res Public Health. 2017;14(11). pii: E1347. doi: 10.3390/ijerph14111347

59. Garbarino, S.; Magnavita, N. Sleep problems are a strong predictor of stress-related metabolic changes in police officers. A prospective study. PLoS One. 2019;14(10):e0224259. doi: 10.1371/journal.pone.0224259.

60. Garbarino, S.; Tripepi, G.; Magnavita, N. Sleep health promotion in the workplace. Int J Environ Res Public Health. 2020;17(21):E7952. doi: 10.3390/ijerph17217952

61. RAI, le foto simbolo di un'Italia che non dimenticheremo mai - RaiNews 28 Dec 2020, Available at: https://www.rainews.it/dl/rainews/media/2020-le-foto-simbolo-di-un-italia-che-non-dimenticheremo-mai-d2bec588-9ef7-452b-93a2-d7b265f94bfb.html\#foto-1 